\title{
Improving the potency of DNA vaccine encoding HIV-1 Nef antigen using two endogenous adjuvants in mouse model
}

\author{
Jafarzade $\mathrm{BS}^{1,2}$, Sadat $\mathrm{SM}^{3}$, Yaghobi $\mathrm{R}^{4}$, Bolhassani $\mathrm{A}^{3}$ \\ Department of Microbiology College of Science, Science and Research Branch Islamic Azad University, \\ Fars, Iran. azam.bolhassani@yahoo.com
}

\begin{abstract}
BACKGROUND: DNA immunization can induce long-term immune responses, which are required to design an effective HIV vaccine. It was shown that antigen-expressing plasmids can increase the protective immunity against infectious diseases such as: influenza and malaria. However, DNA-based immunizations have poor immunogenicity, thus the use of potent immunoadjuvants can enhance their potency.

METHODS: In the current study, preparation of the recombinant HIV-1 Nef, Gp96 and HMGB1 DNA constructs was performed in bacterial system. Then, the immunogenicity of DNA construct harboring HIV-1 Nef gene (pcDNANef) was studied using two endogenous adjuvants (pcDNA-HMGB1 and pcDNA-Gp96) in BALB/c mouse model. RESULTS: Our data showed that co-injection of pcDNA-Nef with pcDNA-HMGB1 effectively raised both humoral and cell-mediated immune responses in mice as compared to pcDNA-Nef adjuvanted with pcDNA-gp96. Indeed, co-immunization of HIV-1 Nef DNA with HMGB1 DNA significantly induced high levels of IgG2a and IFN-y directed toward Th1 responses and also cytotoxic T lymphocytes (CTLs) activity in comparison with other immunized groups. CONCLUSION: These findings suggest that the full length of HMGB1 gene could be a more efficient adjuvant for improvement of therapeutic HIV DNA-based immunization compared to the full length of gp96 gene (Tab. 1, Fig. 3, Ref. 58). Text in PDF www.elis.sk.

KEY WORDS: HIV-1 Nef, Gp96, HMGB1, adjuvant, therapeutic vaccine.
\end{abstract}

\section{Introduction}

Human immunodeficiency virus type1 (HIV-1) infection is one of the most fatal infections worldwide; thus development of an effective vaccine is required to prevent or treat HIV-related acquired immune deficiency syndrome (AIDS) (1). Among the accessory proteins encoded by HIV genome (Vif, Vpr, Vpu and $\mathrm{Nef})$, Nef protein $(\sim 27-32 \mathrm{kDa})$ was indicated to be necessary for high viral load and progression to AIDS (2-10). Some Nef activities include down-regulation of cell-surface viral receptors (CD4/CXCR4/CCR5), remodelling of the actin cytoskeleton, and stimulation of host cell signalling pathways in both macrophages and lymphocytes (11-16). This protein has multiple conserved and immunogenic epitopes, which are recognized by cytotoxic and $\mathrm{T}$ helper lymphocytes $(17,18)$. Therefore, Nef might be a good candidate for HIV vaccine design due to its expression during early viral replication, high immunogenicity and key role in HIV pathogenicity (17-19). The studies showed that DNA-based

\footnotetext{
${ }^{1}$ Department of Microbiology College of Science, Science and Research Branch Islamic Azad University, Fars, Iran, ${ }^{2}$ Department of Microbiology, College of Science, Agriculture and Modern Technology, Shiraz Branch Islamic Azad University, Shiraz, Iran, ${ }^{3}$ Department of Hepatitis and AIDS, Pasteur Institute of Iran, Tehran, Iran, and ${ }^{4}$ Shiraz Transplant Research Center, Shiraz University of Medical Sciences, Shiraz, Iran
}

Address for correspondence: A. Bolhassani, $\mathrm{PhD}$, Department of Hepatitis and AIDs, Pasteur Institute of Iran, Tehran, Iran.

Phone: +98.21.66953311, Fax: +98.21.66465132 vaccines are among different approaches, which are capable to generate antigen-specific immune responses in vaccinated animals and humans $(20,21)$. However, despite several properties including ease of manufacturing, cost effectiveness and safety in DNA vaccines, they have poor immunogenicity. A main strategy to enhance the potency of DNA-based vaccines is the use of immunoadjuvants (22). In recent years, heat shock proteins (HSPs) have been recognized as potent adjuvants in immunotherapy of cancer and infectious disease (23). Gp96, a member of HSP90 family, has been reported to play an important role in innate and adaptive immune responses (24). Nicchitta et al. reported that GP96 could potently stimulate maturation of antigen presenting cells and secretion of pro inflammatory cytokines (25). The efficiency of Gp96 gene was studied in both conjugated and co-injected forms with DNA vaccines containing some viral and bacterial antigens $(26,27)$. On the other hand, high mobility group box 1 (HMGB1) protein, a chromatin-associated protein with high acidic and basic amino acid content $(\sim 25 \mathrm{kDa})$ has been shown to act as a mediator of inflammation (28-30). Indeed, HMGB1 acts as an extracellular signalling molecule during inflammation, cell differentiation, cell migration, and tumour metastasis $(31,32)$. HMGB1 has been identified as a damage-associated molecular pattern molecule (DAMP) and could interact with pattern recognition receptors such as RAGE and TLRs (33-35). It has been reported to be involved in host responses to infections, injuries, tumours, and inflammation by promoting cytokine production, recruiting immune cells, and modulating DC migration and maturation (36-38). These prop- 
erties make HMGB1 a potential vaccine adjuvant. Regarding the major immuno-stimulatory activities of Gp96 and HMGB1 as endogenous adjuvants, in the current study, their efficacy was compared in DNA-based immunization strategy using HIV-1 Nef as a candidate antigen in $\mathrm{BALB} / \mathrm{c}$ mice model.

\section{Materials and Methods}

Large scale preparation of endotoxin-free plasmids (pcDNA-Nef, pcDNA-gp96, pcDNA-HMGB1)

The pUC-19 cloning vector harboring the complete Nef open reading frame (pUC-Nef) was synthesized by Biomatik Company (Canada). The HIV-1 Nef gene was cloned into the NheI/BamHI sites of the pcDNA 3.1 eukaryotic vector. The gp96 and HMGB1 genes were previously cloned into the BamHI/KpnI and NotI/EcoRI sites of the pcDNA3.1 (-) vector (Invitrogen) $(39,40)$. Herein, a large-scale purification of plasmid DNA samples (pcDNA3.1, pcDNA-HMGB1, pcDNA-Nef and pcDNA-Gp96) was performed using ion-exchange chromatography with an Endofree plasmid Giga kit (QIAGEN) according to the manufacturer's instructions for mice immunization. Then, the presence of the inserted Nef, gp96, and HMGB1 fragments was confirmed by PCR, digestion and sequencing. Finally, the concentration and purity of DNA constructs were determined by NanoDrop spectrophotometer and stored in endotoxin-free PBS1X at $-20^{\circ} \mathrm{C}$ until used.

Preparation of the recombinant Nef protein

The Nef protein was expressed in the E.coli BL21 using Isopropyl- $\beta$-D-thiogalactopyranoside (IPTG, $1 \mathrm{mM}$ ) and purified by reverse staining method as previously reported (41). Next, the recombinant protein was quantified using a NanoDrop spectrophotometry.

Mice immunization

Six to eight week old female BALB/c mice ( $n=4$ per group) were obtained from breeding stock, maintained at the Pasteur Institute of Iran. Mice were subcutaneously immunized on days 0 , 14 , and 28 in three groups with $100 \mu \mathrm{g}$ of pcDNA-Nef in PBS (G1), and pcDNA-Nef adjuvanted with pcDNA-gp96 (G2) or pcDNA-HMGB1 (G3). Table 1 shows the regimens of DNA immunizations at different times.

Determination of antibody levels

Pooled sera were prepared after retro-orbital bleeding from the whole blood samples of each group, three weeks after the last immunization. The levels of Nef-specific antibodies (total IgG, IgG1, IgG2a conjugated to peroxidase, Southern biotechnology Association, USA) in the sera were determined using indirect ELISA as previously described (40).

\section{In vitro cytokine release}

Three weeks after the last immunization, three mice from each group were sacrificed randomly and the spleens were removed. The red blood cell depleted pooled splenocytes $\left(2 \times 10^{6}\right.$ cells $\left./ \mathrm{ml}\right)$ were cultured in U-bottomed, 96-well plates for $72 \mathrm{~h}$ in the presence of $10 \mu \mathrm{g} / \mathrm{ml}$ of rNef protein, RPMI 5\% (negative control), and $5 \mu \mathrm{g} / \mathrm{ml}$ of concanavalin A (ConA, positive control) in complete culture medium. The presence of IFN- $\gamma$ and IL-4 in supernatants was measured using a DuoSet sandwich-based on ELISA system (R\&D) according to the manufacturer's instructions.

Granzyme B (GrB) ELISA assay

SP2/0 target cells $(\mathrm{T})$ were seeded in triplicate into U-bottomed, 96-well plates $\left(2 \times 10^{4}\right.$ cells/ well $)$ incubated with Nef antigen $(\sim 30 \mu \mathrm{g} / \mathrm{ml})$ for $24 \mathrm{~h}$. The pooled splenocytes of mice in each group (Effector cells: E) were counted using trypan blue and added to the target cells at E: T ratio of 100:1, in which a maximal release of Granzyme B was observed. The target and effector cells were co-cultured in complete RPMI-1640 supplemented with $10 \%$ heat-inactivated $\mathrm{FCS}$ at $37^{\circ} \mathrm{C}$ and $5 \% \mathrm{CO}_{2}$ under humidified conditions. The wells containing effector cells were considered for measurement of possible spontaneous release of Granzyme B. After $6 \mathrm{~h}$ incubation, microplates were centrifuged at $250 \times \mathrm{g}$ for 5 min at $4^{\circ} \mathrm{C}$ and the supernatants were harvested. The concentration of Granzyme B in these samples was measured by ELISA (eBioscience, USA) according to the manufacturer's instruction. Statistical analysis

The differences between the control and test groups were assessed using one-way ANOVA (GraphPad Software, USA). A pvalue $<0.05$ was statistically considered significant.

\section{Results}

Preparation of the recombinant DNA plasmids and Nef protein

DNA constructs encoding HIV-1 Nef, Gp96, and HMGB1 (pcDNA-Nef, pcDNA-Gp96, pcDNA-HMGB1) were prepared in large scale with a high purity. The presence of Nef, Gp96, and HMGB1 genes was confirmed using digestion and PCR analysis as clear bands of $\sim 648 \mathrm{bp}, \sim 2550 \mathrm{bp}$, and $\sim 645 \mathrm{bp}$ migrated in agarose gel, respectively and sequencing. Moreover, the purified GST-Nef (rNef) protein migrated as a clear band of $\sim 50 \mathrm{kDa}$ in SDS-PAGE as previously reported (41). Figure 1 shows the PCR products of Nef, Gp96 and HMGB1 in agarose gel.

Evaluation of antibody responses in immunized mice

To compare humoral immune responses induced in various groups, the serum levels of total IgG and their subclasses (IgG1, IgG2a) against rNef protein were detected using indirect ELI-

Tab. 1. Immunization schedule in mouse model.

\begin{tabular}{lcccc}
\hline Groups & Vaccine modality & Priming & $\begin{array}{c}\text { Booster 1 } \\
\text { (2 weeks after priming) }\end{array}$ & $\begin{array}{c}\text { Booster 2 } \\
(2 \text { weeks after booster 1) }\end{array}$ \\
\hline G1 & DNA & pcDNA-Nef & pcDNA-Nef & pcDNA-Nef \\
G2 & DNA & pcDNA-Nef+pcDNA-gp96 & pcDNA-Nef+pcDNA-gp96 & pcDNA-Nef+pcDNA-gp96 \\
G3 & DNA & pcDNA-Nef+pcDNA-HMGB1 & pcDNA-Nef+pcDNA-HMGB1 & pcDNA-Nef+pcDNA-HMGB1 \\
G4 & PBS (control) & PBS & PBS & PBS \\
G5 & Empty vector (control) & pcDNA3.1 & pcDNA3.1 & pcDNA3.1 \\
\hline
\end{tabular}



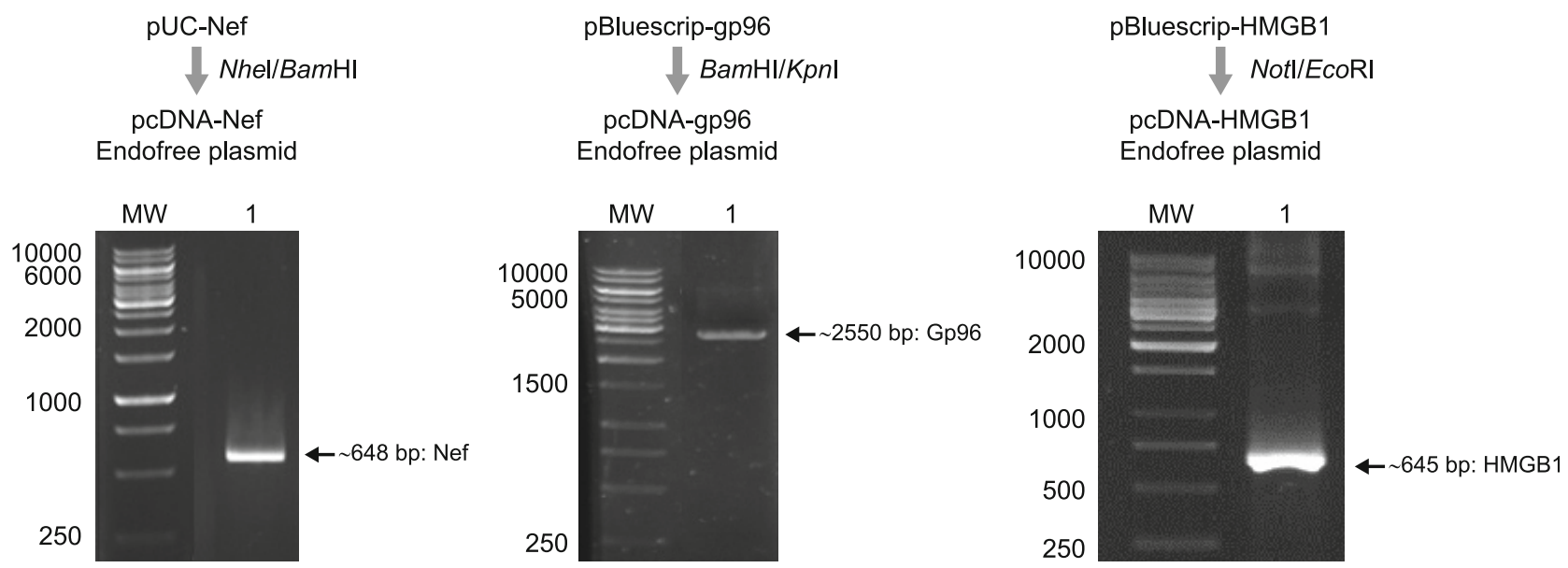

Fig. 1. Confirmation of HIV-1 Nef, Gp96 and HMGB1 genes cloned in pcDNA 3.1 using PCR. MW is molecular weight marker (Fermentas).

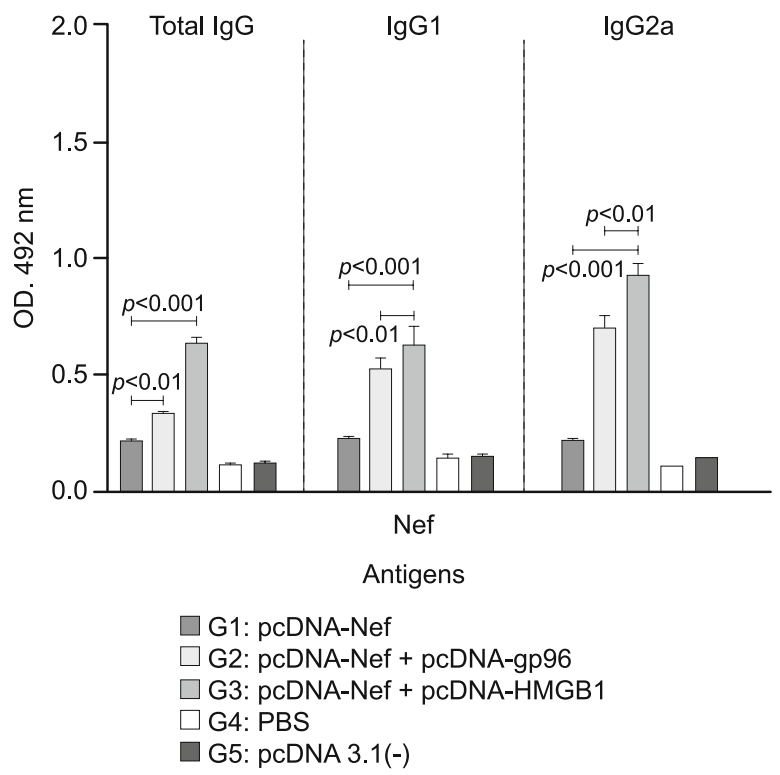

Fig. 2. Analysis of total IgG, IgG1, and IgG2a antibody levels with respect to rNef in each group using indirect ELISA. Data are shown as mean $\pm \mathrm{SD}$.

SA (Figure 2). Our data showed that the levels of total IgG and other isotypes in the sera of mice immunized with pcDNA-Nef + pcDNA-HMGB1 (G3) was significantly higher than those in the groups immunized with other DNA constructs (G1 \& G2; $p$ $<0.05$ ). On the other hand, the level of IgG2a in groups immunized with pcDNA-Nef + pcDNA-HMGB1 (G3) was significantly higher than the level of IgG1 in this group $(p<0.05)$. Moreover, the levels of total IgG and also isotypes in the sera of mice immunized with pcDNA-Nef + pcDNA-gp96 (G2) were higher than in the group immunized with pcDNA-Nef, alone (G1), indicating the role of Gp96 as an adjuvant. In general, all test groups showed high antibody responses as compared to the control groups $(p<$ 0.05 , Figure 2).
Cytokine assay

The cytokine results showed that Nef + HMGB1 DNA construct (G3) was more effective than Nef + Gp96 DNA (G2) and Nef DNA (G1) in eliciting IFN- $\gamma$ responses $(p<0.05$, Figure 3A). Furthermore, both HMGB1 and Gp96 could increase the secretion of IFN- $\gamma$ in group immunized with Nef DNA (G2 and G3) as compared to the group immunized with Nef DNA construct (G1, $p<0.05)$. All DNA immunization effectively enhanced the levels of IFN- $\gamma$ as compared to the control groups $(p<0.05)$. The test groups did not show any significant IL-4 responses in comparison with the control groups ( $p>0.05$, data not shown).

Granzyme B secretion

Three weeks after the last immunization, splenocytes from each immunized group were co-cultured with SP2/0 target cells in E: T ratio of 100:1 for $6 \mathrm{~h}$ at $37^{\circ} \mathrm{C}$, and the supernatants were harvested. Granzyme B secretion in each sample was measured by ELISA (Figure 3B). Group immunized with pcDNA-Nef + pcDNA-HMGB1 (G3) produced a significantly higher concentration of Granzyme B than all other groups $(p<0.001)$. Indeed, the Granzyme B secretion was significantly higher in the group immunized with Nef + HMGB1 DNA (G3) compared to the group immunized with Nef + Gp96 (G2, p < 0.05), suggesting the effective role of HMGB1 as an adjuvant in DNA immunization. Control groups including mice injected with PBS or empty vector (pcDNA 3.1) had granzyme B concentrations below the minimum detectable range of ELISA (40-5000 pg/ml). All results showed a direct relationship between antibody responses, IFN- $\gamma$ production, and Granzyme B secretion as a possible indicator of CTL activity.

\section{Discussion}

The studies showed that DNA-based vaccines emerged as a successful approach for generation of antigen-specific immune responses against viral diseases. Due to low immunogenicity of this strategy, some adjuvants were considered to increase its potency. Some studies have been focused on HIV-1 Nef as an important 


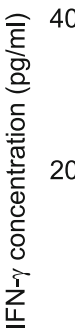

A
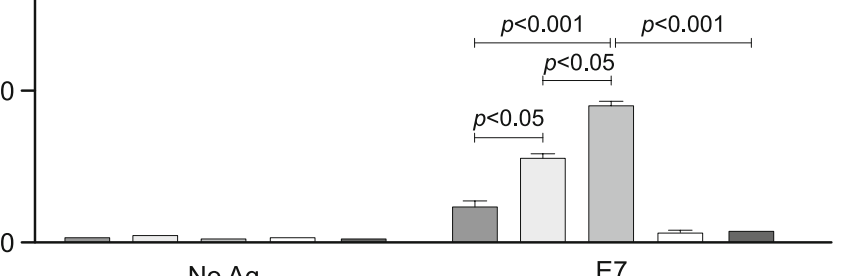

No Ag

Antigens
E7

$\square$ G1: pcDNA-Nef

$\square$ G2: pcDNA-Nef + pcDNA-gp96

$\square$ G3: pcDNA-Nef + pcDNA-HMGB1

$\square$ G4: PBS

$\square$ G5: pcDNA 3.1(-)

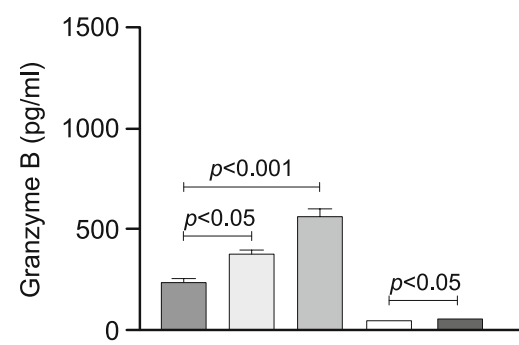

(B)

Fig. 3. A) IFN- $\gamma$ levels in immunized groups with various formulations: Pooled splenocyte cultures were re-stimulated with rNef in vitro. The detection limit was $2 \mathrm{pg} / \mathrm{ml}$ for IFN- $\gamma$ and $7 \mathrm{pg} / \mathrm{ml}$ for IL-4; B) Granzyme B concentration measured by ELISA: The results represent mean values calculated from triplicate samples as well as the standard deviation (SD) as error bars.

component for development of HIV vaccines. For example, immunogenicity of Nef encoded by Modified Vaccinia virus Ankara (MVA) and by plasmid DNA was evaluated in BALB/c mice model. The results showed that DNA construct expressing Nef elicited long-lasting $\mathrm{CD} 8^{+} \mathrm{T}$ cell memory responses, while MVA expressing Nef induced $\mathrm{CD}^{+} \mathrm{T}$ cell memory responses. Indeed, the type of the expression vector could direct the responses towards $\mathrm{CD} 4^{+}$or $\mathrm{CD} 8^{+} \mathrm{T}$ cell responses (42). In this study, we evaluated immune responses induced by various DNA immunizations in BALB/c mice model. Two adjuvants such as HMGB1 and Gp96 were utilized to enhance the efficiency of Nef as a candidate antigen. Heat shock proteins have been proposed as important immunostimulatory molecules to increase antigen-specific immunity $(43,44)$. Our previous studies indicated the adjuvant activity of Gp96 along with HPV16 E7 in different immunization strategies (40). One study indicated that anti-Nef antibodies in mice immunized with pBN-Nef were detected within four weeks after the last immunization, whereas mice immunized with pCGE2-Nef had poor anti-Nef antibodies (45). Other data showed that HIV-1 Nef DNA vaccine (pcDNA-Nef) could induce anti-Nef antibodies and Nef-specific CTL activity, but stronger specific immune responses were stimulated in mice receiving pcDNA-Nef along with LIGHT expression plasmid (LIGHT, a member of TNF superfamily), suggesting that the LIGHT could be considered as a gene adjuvant for HIV-1 DNA vaccination (46). Herein, we also showed that Gp96 as an adjuvant could increase immune responses induced by pcDNA-Nef regimen. On the other hand, we indicated that DNA immunization with Nef + HMGB1 DNA induced potent humoral and cellular immune responses directed toward Th1 responses. Immunization with Nef + HMGB1 DNA could induce a significant increase in Granzyme B release $(\sim 600 \mathrm{pg} / \mathrm{ml})$ as compared to other groups. Indeed, the presence of HMGB1 could stimulate Granzyme B secretion as a possible indicator of CTL activity against re-stimulation with $\mathrm{Nef}$ antigen. Our results showed that there was a similarity between IFN- $\gamma$ production and Granzyme B secretion. Indeed, the group immunized with Nef + HMGB1
DNA demonstrated the highest levels of IFN- $\gamma$ and Granzyme B as compared to the other groups. In general, production of IgG2a was significantly higher in groups immunized with Nef DNA adjuvanted with HMGB1 as compared to other regimens. All three DNA immunizations could significantly generate IgG isotypes and IFN- $\gamma$ against Nef-coated antigens compared to the control groups. Our results showed that both HMGB1 and Gp96 as an adjuvant in DNA-immunized groups could elicit higher humoral and cellular responses than DNA regimen alone (i.e., pcDNA-Nef). In general, there is a great interest in developing adjuvant formulations for the design of therapeutic HIV vaccines based on nucleic acids. The use of novel and safe adjuvants stimulating the Th1-type immune response could improve therapeutic vaccines against pathogens and cancers. The studies showed that HMGB1 could increase the primary antibody responses to soluble antigens and alter poorly immunogenic apoptotic lymphoma cells into effective vaccines (47). Others have shown that HMGB1 induces the secretion of IL-2 and IFN- $\gamma$ secretion from allogeneic $\mathrm{T}$ cells, suggesting the induction of the Th1-biased immune response (48). One report also showed that the fusion of HMGB1 with the VP1 antigen could enhance the immunogenicity of DNA vaccine (49). In this study, the mice were subcutaneously injected with HMGB1 DNA; thus, HMGB1 could not directly entry into the systemic circulation indicating the absence of autoantibodies or septic shock in vaccinated groups as observed in other studies (50). Other studies showed that an immunomodulatory protein (HMGB1) could act as a molecular adjuvant in DNA vaccination against HIV and influenza viruses in co-administration with antigens (51-53). Our data indicated that IL-4 did not show any considerable response in immunized mice. Indeed, the secretion of IFN- $\gamma$ along with undetectable IL-4 suggested that HMGB1 induceed the Th1 immune response in vivo.

DNA vaccines have the potential to be an ideal therapeutic approach against HIV-1. The potency of DNA vaccines has been greatly increased by new formulations and delivery methods (5457). Intradermal injection of mice with plasmid DNA encoding HIV-1 Nef protein was shown to induce Nef-specific T and B cell 
responses. Co-injection of mice with a plasmid DNA encoding HIV-1 Nef protein and the expression vector encoding murine granulocyte-macrophage colony-stimulating factor (GM-CSF cytokine) led to enhanced Nef-specific T cell responses and antibody levels. However, the immunostimulatory activity of GM-CSF DNA was locally limited and observed only if both plasmids were administrated at the same site (58). Altogether, our data demonstrated that mice immunization with Nef + HMGB1 DNA induced Th1 response and also strong Granzyme B secretion suggesting a higher activity of HMGB1 compared to Gp96 in DNA immunization.

\section{Conclusion}

In summary, this study indicated the effects of HMGB1 and Gp96 as two endogenous adjuvants to enhance the efficiency of DNA constructs expressing HIV-1 Nef antigen. The data showed that HMGB1 could significantly increase the potency of vaccine as compared to Gp96 adjuvant. However, further studies are needed to optimize this strategy in Future.

\section{References}

1. Allen TM, Vogel TU, Fuller DH, Mothé BR, Steffen S, Boyson JE, Shipley T, Fuller J, Hanke T, Sette A, Altman JD, Moss B, McMichael AJ, Watkins DI. Induction of AIDS virus-specific CTL activity in fresh, un-stimulated peripheral blood lymphocytes from rhesus macaques vaccinated with a DNA prime/modified vaccinia virus Ankara boost regimen. J Immunol 2000; 164 (9): 4968-4978.

2. Collins KL, Chen BK, Kalams SA, Walker BD, Baltimore D. HIV-1 Nef protein protects infected primary cells against killing by cytotoxic $\mathrm{T}$ lymphocytes. Nature 1998; 391: 397-401.

3. Schwartz O, Maréchal V, Le Gall S, Lemonnier F, Heard JM. Endocytosis of major histocompatibility complex class I molecules is induced by the HIV-1 Nef protein. Nat Med 1996; 2(3): 338-342.

4. Shah AH, Sowrirajan B, Davis ZB, Ward JP, Campbell EM, Planelles V, Barker E. Degranulation of natural killer cells following interaction with HIV-1-infected cells is hindered by down-modulation of NTB-A by Vpu. Cell Host Microbe 2010; 8: 397-409.

5. Matusali G, Potesta M, Santoni A, Cerboni C, Doria M. The human immunodeficiency virus type $1 \mathrm{Nef}$ and $\mathrm{Vpu}$ proteins down-regulate the natural killer cell-activating ligand PVR. J Virol 2012; 86: 4496-504.

6. Kestler HW, Ringler DJ, Mori K, Panicali DL, Sehgal PK, Daniel MD, Desrosiers RC. Importance of the nef gene for maintenance of high virus loads and for development of AIDS. Cell 1991; 65: 651-662.

7. Lee CH, Saksela K, Mirza UA, Chait BT, Kuriyan J. Crystal structure of the conserved core of HIV-1 Nef complexed with a Src family SH3 domain. Cell 1996; 85: 931-942.

8. Arold S, Franken P, Strub MP, Hoh F, Benichou S, Benarous R, Dumas C. The crystal structure of HIV-1 Nef protein bound to the Fyn kinase SH3 domain suggests a role for this complex in altered $\mathrm{T}$ cell receptor signaling. Structure 1997; 5: 1361-1372.

9. Grzesiek S, Bax A, Hu JS, Kaufman J, Palmer I, Stahl SJ, Tjandra N, Wingfield PT. Refined solution structure and backbone dynamics of HIV-1 Nef. Protein Sci 1997; 6: 1248-1263.

10. Franken P, Arold S, Padilla A, Bodeus M, Hoh F, Strub MP, Boyer M, Jullien M, Benarous R, Dumas C. HIV-1 Nef protein: purification, crystallizations, and preliminary X-ray diffraction studies. Protein Sci 1997; 6: $2681-2683$.

11. Foster JL, Garcia JV. HIV-1 Nef: At the crossroads. Retrovirology 2008; 5: 84.

12. Xu XN, Laffert B, Screaton GR, Kraft M, Wolf D, Kolanus W, Mongkolsapay J, McMichael AJ, Baur AS. Induction of Fas ligand expression by HIV involves the interaction of Nef with the T cell receptor zeta chain. J Exp Med 1999; 189: 1489-1496.

13. Geleziunas R, Xu W, Takeda K, Ichijo H, Greene WC. HIV-1 Nef inhibits ASK1-dependent death signaling providing a potential mechanism for protecting the infected host cell. Nature 2001; 410: 834-838.

14. Wolf D, Witte V, Laffert B, Blume K, Stromer E, Trapp S, d'Aloja P, Schürmann A, Baur AS. HIV-1 Nef associated PAK and PI3-kinases stimulate Akt-independent Bad-phosphorylation to induce anti-apoptotic signals. Nat Med 2001; 7: 1217-1224.

15. Olivetta E, Federico M. HIV-1 Nef protects human monocyte-derived macrophages from HIV-1 induced apoptosis. Exp Cell Res 2006; 312: 890900.

16. Hanna Z, Priceputu E, Kay DG, Poudrier J, Chrobak P, Jolicoeur P. In vivo mutational analysis of the N-terminal region of HIV-1 Nef reveals critical motifs for the development of an AIDS-like disease in CD4C/HIV transgenic mice. Virology 2004; 327 (2): 273-286.

17. Brave A, Gudmundsdotter L, Gasteiger G, Hallermalm K, Kastenmuller W, Rollman E, Boberg A, Engström G, Reiland S, Cosma A, Drexler I, Hinkula J, Wahren B, Erfle V. Immunization of mice with the nef gene from Human Immunodeficiency Virus type 1: study of immunological memory and long-term toxicology. Infect Agent Cancer 2007; 2: 14.

18. Liang X, Fu TM, Xie H, Emini EA, Shiver JW. Development of HIV1 Nef vaccine components: immunogenicity study of Nef mutants lacking myristoylation and dileucine motif in mice. Vaccine 2002; 20 (27-28): 3413-3421

19. Cazeaux N, Bennasser Y, Vidal PL, Li Z, Paulin D, Bahraoui E. Comparative study of immune responses induced after immunization with plasmids encoding the HIV-1 Nef protein under the control of the CMV-IE or the muscle-specific desmin promoter. Vaccine 2002; 20 (27-28): 3322-3331.

20. Donnelly JJ, Wahren B, Liu MA. DNA vaccines: progress and challenges. J Immunol 2005; 175 (2): 633-639.

21. Widera G, Austin M, Rabussay D, Goldbeck C, Barnett SW, Chen M, Leung L, Otten GR, Thudium K, Selby MJ, Ulmer JB. Increased DNA vaccine delivery and immunogenicity by electroporation in vivo. $\mathrm{J}$ Immunol 2000; 164 (9): 4635-4640.

22. El-Aneed A. An overview of current delivery systems in cancer gene therapy. J Control Release 2004; 94 (1): 1-14.

23. Binder RJ. Heat shock protein-based vaccines for cancer and infectious disease. Expert Rev Vaccine 2008; 7: 383-393.

24. Nicchitta CV. Re-evaluating the role of heat-shock protein peptide interactions in tumor immunity. Nat Rev Immunol 2003; 3: 427-432.

25. Baker-LePain JC, Sarzotti M, Nicchitta CV. Glucose-regulated protein 94/glycoprotein 96 elicits bystander activation of $\mathrm{CD}^{+} \mathrm{T}$ cell $\mathrm{Th} 1$ cytokine production in vivo. J Immunol 2004; 172: 4195-4203.

26. Bolhassani A, Zahedifard F, Taghikhani M, Rafati S. Enhanced immunogenicity of HPV16E7 accompanied by Gp96 as an adjuvant in two vaccination strategies. Vaccine 2008; 26: 3362-3370.

27. Rapp UK, Kaufmann SH. DNA vaccination with gp96-peptide fusion proteins induces protection against an intracellular bacterial pathogen. Int Immunol 2004; 16: 597-605. 
28. Degryse B, Bonaldi T, Scaffidi P, Muller S, Resnati M, Sanvito F, Arrigoni G, Bianchi ME. The high mobility group (HMG) boxes of the nuclear protein HMG1 induce chemotaxis and cytoskeleton reorganization in rat smooth muscle cells. J Cell Biol 2001; 152: 1197-1206.

29. Dumitriu IE, Baruah P, Valentinis B et al. Release of high mobility group box 1 by dendritic cells controls $\mathrm{T}$ cell activation via the receptor for advanced glycation end products. J Immunol 2005; 174: 7506-7515.

30. Lotze MT, Tracey KJ. High-mobility group box 1 protein (HMGB1): nuclear weapon in the immune arsenal. Nat Rev Immunol 2005; 5: 331-342.

31. Dong XD, Ito N, Lotze MT, Demarco RA, Popovic P, Shand SH, Watkins S, Winikoff S, Brown CK, Bartlett DL, Zeh HJ. High Mobility Group Box I (HMGB1) Release From Tumor Cells After Treatment: Implications for Development of Targeted Chemoimmunotherapy. J Immunother (1997) 2007; 30: 596-606.

32. Ellerman JE, Brown CK, de Vera M, Zeh HJ, Billiar T, Rubartelli A, Lotze MT. Masquerader: high mobility group box-1 and cancer. Clin Cancer Res 2007; 13: 2836-2848.

33. Park JS, Gamboni-Robertson F, He Q et al. High mobility group box 1 protein interacts with multiple Toll-like receptors. Am J Physiol Cell Physiol 2006; 290: C917-924.

34. Kokkola R, Andersson A, Mullins G, Ostberg T, Treutiger CJ, Arnold B, Nawroth P, Andersson U, Harris RA, Harris HE. RAGE is the major receptor for the proinflammatory activity of HMGB1 in rodent macrophages. Scand J Immunol 2005; 61: 1-9.

35. Forbes EK, Sander C, Ronan EO, McShane H, Hill AV, Beverley PC, Tchilian EZ. Multifunctional, high-level cytokine-producing Th1 cells in the lung, but not spleen, correlate with protection against Mycobacterium tuberculosis aerosol challenge in mice. J Immunol 2008; 181: 4955-4964.

36. Lindenstrom T, Agger EM, Korsholm KS, Darrah PA, Aagaard C, Seder RA, Rosenkrands I, Andersen P. Tuberculosis subunit vaccination provides long-term protective immunity characterized by multifunctional CD4 memory T cells. J Immunol 2009; 182: 8047-8055.

37. Aagaard CS, Hoang TT, Vingsbo-Lundberg C, Dietrich J, Andersen P. Quality and vaccine efficacy of CD4+ T cell responses directed to dominant and subdominant epitopes in ESAT-6 from Mycobacterium tuberculosis. J Immunol 2009; 183: 2659-2668.

38. Hoang TT, Nansen A, Roy S, Billeskov R, Aagaard C, Elvang T, Dietrich J, Andersen P. Distinct differences in the expansion and phenotype of TB10.4 specific CD8 and CD4 T cells after infection with Mycobacterium tuberculosis. PLoS One 2009; 4: e5928.

39. Talebi S, Bolhassani A, Sadat SM, Vahabpour R, Agi E, Shahbazi S. Hp91 immunoadjuvant: An HMGB1-derived peptide for development of therapeutic HPV vaccines. Biomed Pharmacother 2017; 85: 148-154.

40. Bolhassani A, Zahedifard F, Taghikhani M, Rafati S. Enhanced immunogenicity of HPV16E7 accompanied by Gp96 as an adjuvant in two vaccination strategies. Vaccine 2008; 26: 3362-3370.

41. Jafarzade BS, Bolhassani A, Sadat SM, Yaghobi R. Delivery of HIV1 Nef protein in mammalian cells using cell penetrating peptides as a candidate therapeutic vaccine. International Journal of Peptide Research and Therapeutics 2017; 23 (1): 145-153.

42. Brave A, Gudmundsdotter L, Gasteiger G, Hallermalm K, Kastenmuller W, Rollman E, Boberg A, Engström G, Reiland S, Cosma A, Drexler I, Hinkula J, Wahren B, Erfle V. Immunization of mice with the nef gene from human immunodeficiency virus type 1: study of immunological memory and long-term toxicology. Infect Agent Cancer 2007; 2: 14.

43. Bolhassani A, Rafati S. Heat-shock proteins as powerful weapons in vaccine development. Expert Rev Vaccines 2008; 7: 1185-1199.
44. Mohit E, Bolhassani A, Zahedifard F, Taslimi Y, Rafati S. The contribution of NT-gp96 as an adjuvant for increasing HPV16 E7-specific immunity in C57BL/6 mouse model. Scand J Immunol 2012; 75: 27-37.

45. Collings A, Pitkanen J, Strengell M, Tahtinen M, Lagerstedt A, Hakkarainen K. Humoral and cellular immune responses to HIV-1 Nef in mice DNA-immunized with non-replicating or self-replicating expression vectors. Vaccine 1999; 18: 460-467.

46. Wen J, Hao W, Fan Y, Du J, Du B, Qian M, Jiang W. Co-delivery of LIGHT expression plasmid enhances humoral and cellular immune responses to HIV-1 Nef in mice. Arch Virol 2014; 159: 1663-1669.

47. Rovere-Querini P, Capobianco A, Scaffidi P, Valentinis B, Catalanotti F, Giazzon M, Dumitriu IE, Müller S, Iannacone M, Traversari C, Bianchi ME, Manfredi AA. HMGB1 is an endogenous immune adjuvant released by necrotic cells. EMBO Rep 2004; 5 (8): 825-830.

48. Messmer D, Yang H, Telusma G, Knoll F, Li J, Messmer B, Tracey KJ, Chiorazzi N. High mobility group box protein 1: an endogenous signal for dendritic cell maturation and Th1 polarization. J Immunol 2004; 173: $307-313$

49. Williman J, Young S, Buchan G, Slobbe L, Wilson M, Pang P, Austyn J, Preston S, Baird M. DNA fusion vaccines incorporating IL-23 or RANTES for use in immunization against influenza. Vaccine 2008; 26: 5153-5158.

50. Tian J, Avalos AM, Mao SY, Chen B, Senthil K, Wu H, Parroche P, Drabic S, Golenbock D, Sirois C, Hua J, An LL, Audoly L, La Rosa G, Bierhaus A, Naworth P, Marshak-Rothstein A, Crow MK, Fitzgerald KA, Latz E, Kiener PA, Coyle AJ. Toll-like receptor 9-dependent activation by DNA containing immune complexes is mediated by HMGB1 and RAGE. Nat Immunol 2007; 8: 487-496.

51. Muthumani G, Laddy DJ, Sundaram SG, Fagone P, Shedlock DJ, Kannan S, Wu L, Chung CW, Lankaraman KM, Burns J, Muthumani K, Weiner DB. Co-immunization with an optimized plasmid-encoded immune stimulatory interleukin, high-mobility group box 1 protein, results in enhanced interferon-c secretion by antigen-specific CD8 T cells. Immunol 2009; 128: e612-620.

52. Fagone P, Shedlock DJ, Bao H, Kawalekar OU, Yan J, Gupta D, Morrow MP, Patel A, Kobinger GP, Muthumani K, Weiner DB. Molecular adjuvant HMGB1 enhances anti-influenza immunity during DNA vaccination. Gene Ther 2011; 18: 1070-1077.

53. Kobiyama K, Jounai N, Aoshi T, Tozuka M, Takeshita F, Coban C, Ishii KJ. Innate immune signaling and genetic adjuvants for DNA vaccination. Vaccine 2013; 1: 278-292.

54. Fomsgaard A. HIV-1 DNA vaccines. Immunology Letters 1999; 65: $127-31$

55. Giri M, Ugen KE, Weiner DB. DNA vaccines against human immunodeficiency virus type 1 in the past decade. Clinical Microbiology Reviews 2004; 17 (2): 370-389.

56. Ulmer JB, Wahren B, Liu MA. DNA vaccines for HIV/AIDS. Curr Opin HIV AIDS 2006; 1 (4): 309-313.

57. Felber BK, Valentin A, Rosati M, Bergamaschi C, Pavlakis GN. HIV DNA vaccine: Stepwise improvements make a difference. Vaccines 2014; 2: 354-379.

58. Svanholm C, Lowenadler B, Wigzell H. Amplification of $\mathrm{T}$ cell and antibody responses in DNA-based immunization with HIV-1 Nef by co-injection with a GM-CSF expression vector. Scand J Immunol 1997; 46: 298-303.

Received April 27, 2017. Accepted May 12, 2017. 